\title{
Perfil microbiológico, parâmetros físicos e estabilidade aeróbia de silagens de capim-tifton 85 (Cynodon sp.) confeccionadas com distintas concentrações de matéria seca e aplicação de aditivos ${ }^{1}$
}

\author{
Flávio Geraldo Ferreira Castro², Luiz Gustavo Nussio ${ }^{3}$, Cláudio Maluf Haddad, Fábio Prudêncio \\ de Campos ${ }^{4}$, Rodrigo Michelini Coelho ${ }^{5}$, Lucas José Mari ${ }^{6}$, Paulo de Almeida Toledo ${ }^{7}$ \\ ${ }^{1}$ Parte da tese de Doutoramento do primeiro autor apresentada à USP/ESALQ - Piracicaba, SP. Financiamento: CAPES e Fazenda Água \\ Comprida - MG. \\ 2 Agrocria Com. e Ind. Ltda - Goiânia - GO \\ ${ }^{3}$ Departamento de Zootecnia - USP/ESALQ. Av Pádua Dias, 11, CEP: 13418-900 - Piracicaba, SP. \\ 4 Instituto de Zootecnia de Nova Odessa. \\ ${ }^{6}$ Pós-Graduação em Ciência Animal e Pastagens - USP/ESALQ, Piracicaba, SP. \\ ${ }^{7}$ Fazenda Água Comprida, C.P. 174 - CEP: 38010-010 - Uberaba, MG.
}

RESUMO - Objetivou-se com este trabalho avaliar os efeitos do emurchecimento e da aplicação de inoculante bacterianoenzimático (ABE) e ácido propiônico tamponado (APT) sobre o perfil microbiológico, os parâmetros físicos e a estabilidade aeróbia de silagens de capim-tifton 85 (Cynodon spp.) armazenadas em fardos retangulares revestidos por filme plástico. Os tratamentos constaram de cinco silagens $(250,350,450,550$ e $650 \mathrm{~g} / \mathrm{kg} \mathrm{MS})$ sem o aditivo, três $(250,450$ e $650 \mathrm{~g} / \mathrm{kg}$ MS) com aditivo e uma confeccionada com fardos de capim emurchecido até atingir o maior teor de MS (650 g/kg MS), pulverizados com solução contendo ácido propiônico tamponado (APT). O delineamento experimental utilizado foi inteiramente casualizado, com três repetições, em esquema de parcelas subdivididas no tempo, conforme o teor de MS da silagem. Os tratamentos com maiores teores de MS (>450 g/kg MS), em relação àqueles com maior umidade, apresentaram menores contagens de colônias bacterianas, valores intermediários para atividade de água (Aa) e conteúdo de $\mathrm{N}^{-\mathrm{NH}_{3}}$ na silagem e valores superiores para condutividade elétrica (CE), $\mathrm{pH}$ e estabilidade aeróbia. Esses resultados sugerem que o aumento no teor de MS da forragem reduziu a atividade de água (Aa), diminuindo o crescimento de bactérias e, conseqüentemente, a fermentação. O uso do aditivo proporcionou efeito positivo no tratamento com $450 \mathrm{~g} / \mathrm{kg}$ MS, principalmente aos 32 dias de estocagem, enquanto a adição de APT não apresentou vantagens.

Palavras-chave: aditivo bacteriano-enzimático, ácido propiônico, emurchecimento

\section{Effects of additive application on the microbial profile, physical parameters and aerobic stability of Tifton 85 (Cynodon Sp.) silages with different dry matter contents}

\footnotetext{
ABSTRACT - The objectives of this study were to analyze the effects of wilting and bacterial-enzimatic additive (BEA) and buffered propionic acid (BPA) on the microbial profile, physical parameters and aerobic stability of Tifton 85 (Cynodon spp.) silages stored as squared bales $(140 \times 120 \times 70 \mathrm{~cm})$ wrapped with plastic bags. Treatments were based on five forage dry matter (DM) contents $(250,350,450,550$ and $650 \mathrm{~g} / \mathrm{kg} \mathrm{DM})$ without BEA. Other three forage dry matter contents $(250,450$ and $650 \mathrm{~g} \mathrm{k} / \mathrm{g} \mathrm{DM})$ were associated with BEA while a wilted forage $(650 \mathrm{~g} / \mathrm{kg} \mathrm{DM})$ was sprayed with BPA. Silage samples were taken at ensiling time, and after 6 and 12 hours and 1, 2, 4, 8, 16, 32, 90 and 180 days of fermentation. The experimental design was completely randomized with three replications; with DM levels set as the main factor and fermentation time as a split-plot feature of the design. Silages containing higher DM contents (> $450 \mathrm{~g} / \mathrm{kg} \mathrm{DM}$ ) showed lower bacterial counts, intermediary values of water activity (Aw) and silage $\mathrm{N}^{-\mathrm{NH}_{3}}$, and improved values of electrical conductivity (EC), $\mathrm{pH}$ and higher aerobic stability as compared to the wet silages. Results suggest a decrease in Aw followed by an inibition on microorganism growth and silage fermentation as the silage DM increased. The BEA had positive effect on the silage with dry-matter content of $450 \mathrm{~g} / \mathrm{kg}$, mainly on the $32^{\text {nd }}$ day of storage, whereas BPA addition had no benefit.
}

Key Words: bacterial-enzymatic additive, propionic acid, wilting

\section{Introdução}

A obtenção de silagens com padrões qualitativos desejáveis é sempre esperada quando se efetua o processo de conservação de forragens. No entanto, McDonald et al. (1991) mencionam que a quantidade adequada de carboidratos solúveis (CHO’s), o poder tampão relativamente reduzido e a porcentagem de matéria seca acima de

Correspondências devem ser enviadas para: flaviocastro@agrocria.com.br 
$300 \mathrm{~g} / \mathrm{kg}$ são reconhecidas como características importantes para obtenção de padrões desejáveis de fermentação e conservação de forragens por meio da ensilagem.

$\mathrm{Na}$ ensilagem de gramíneas tropicais, considera-se que essas forrageiras possuem concentrações marginais de $\mathrm{CHO}$ na matéria seca bem inferiores às das gramíneas temperadas, além de baixos teores de matéria seca justamente nos estádios de crescimento em que apresentam bom valor nutritivo (McDonald et al., 1991; Vilela, 1998). Essas características colocam em risco o processo de conservação, por favorecer a ocorrência de fermentações secundárias, resultando em maiores perdas de matéria seca(Vilela, 1998).

Durante o processo de ensilagem e depois de alcançada a condição de anerobiose no silo, é importante inibir o crescimento de microrganismos indesejáveis, principalmente as enterobacterias, os clostrídeos e algumas espécies de Bacillus e leveduras, para se evitar que estabeleçam competição por substrato com as bactérias lácticas (McDonald et al., 1991). As alterações ocorridas nos primeiros dias após a ensilagem são críticas para o sucesso da fermentação subseqüente. Se as condições são apropriadas, as bactérias láticas acidificam rapidamente o meio, a uma extensão em que os microrganismos indesejáveis não sobrevivem, resultando em uma silagem estável, com baixo $\mathrm{pH}$. Se o pH não é reduzido rapidamente, os microrganismos indesejáveis podem competir pelos nutrientes, reduzindo as chances de obtenção de uma silagem estável. Portanto, a maneira mais efetiva de se inibir o crescimento de microrganismos indesejáveis é promover a redução da fermentação lática. Um método alternativo para inibição do crescimento de bactérias indesejáveis seria a redução do teor de umidade da forragem pelo emurchecimento do material que antecede a ensilagem (McDonald et al., 1991). A redução na atividade de água $(\mathrm{Aa})$ pode ter um efeito sinergístico adicional na queda do $\mathrm{pH}$ (Lindgren, 1999). As bactérias láticas têm alta tolerância à condição de baixa umidade e podem dominar a fermentação em materiais ensilados com alto conteúdo de matéria seca (McDonald et al., 1991).

Os inoculantes bacterianos são adicionados em silagens para estimular a fermentação lática, resultando em rápida e intensiva produção de ácido lático, o que poderá acelerar a queda do $\mathrm{pH}$, melhorando a preservação e minimizando as perdas (Pitt, 1990).

O manejo de abertura do silo e de remoção da silagem para fornecimento aos animais promove a aeração do ambiente, que era estritamente anaeróbio. Sob essa condição, microrganismos que permaneceram dormentes na ausência de oxigênio multiplicam-se, resultando na deterioração da silagem. Na prática, essa deterioração é geralmente manifestada pelo aumento na temperatura e pelo aparecimento de fungos. Contudo, a taxa de deterioração é muito variável entre os tipos de forragens ensiladas (McDonald et al., 1991).

A deterioração aeróbia das silagens, ocasionada por fungos e leveduras presentes na forragem antes da ensilagem, é indesejável, em razão da grande perda de nutrientes, associada ao baixo consumo voluntário do material e até mesmo à rejeição completa da silagem pelos animais (McDonald et al., 1991). As silagens que apresentam maior susceptibilidade à deterioração aeróbia são aquelas ricas em carboidratos solúveis e amido, como as de milho, ou aquelas em que a fermentação foi restringida pelo uso de aditivos e/ou pelo emurchecimento excessivo da forragem antes da ensilagem.

Atualmente, nos países da Europa e nos Estados Unidos, os aditivos bacterianos são os mais comumente utilizados na ensilagem de milho, gramíneas e leguminosas, as quais podem ser emurchecidas até teores superiores a $300 \mathrm{~g} / \mathrm{kg}$ MS. Essa associação entre o emurchecimento e o uso de aditivo microbiano visa melhorar a fermentação e o valor nutritivo da silagem (Mühlbach, 2000), mas geralmente induzà menor estabilidade aeróbia (Lindgreen, 1999). A adição dos ácidos propiônico e benzóico pode, em alguma extensão, melhorar a estabilidade (Lindgren, 1999). Oácido propiônico tem sido efetivo em evitar a deterioração aeróbia nas silagens tratadas no momento da ensilagem por inibir o crescimento de fungos e, conseqüentemente, reduzir o aquecimento da massa de forragem ensilada (Pitt, 1990).

As enzimas são aditivos biológicos adicionados durante a ensilagem de forragens, para aumentar a disponibilidade de substrato para as bactérias produtoras de ácido lático, pela degradação de carboidratos complexos em carboidratos solúveis (Muck \& Kung, 1997). Pelo processo de hidrólise, as enzimas transformam os carboidratos estruturais em substrato fermentecível para as bactérias láticas (McDonald et al., 1991). Como a concentração de carboidratos solúveis representa um fator limitante para o desenvolvimento de bactérias láticas homofermentativas presentes nos inoculantes bacterianos para silagens, pode-se inferir que a associação de inoculantes bacterianos e enzimas estimula a fermentação de forragens pobres em substratos prontamente fermentescíveis (gramíneas tropicais).

Desse modo, o controle do crescimento de microrganismos torna-se necessário, como forma de maximizar as fermentações desejáveis, para obtenção de produtos mais estáveis e de melhor qualidade nutricional. Nesse contexto, objetivou-se com este estudo determinar o efeito do 
emurchecimento e do uso de aditivo bacteriano-enzimático ou ácido propiônico tamponado na ensilagem sobre o perfil microbiológico, os parâmetros físico-químicos e a estabilidade aeróbia de silagens de capim-tifton 85 (Cynodon spp.).

\section{Material e Métodos}

O experimento foi conduzido na Fazenda Água Comprida (Água Comprida/MG), localizada nas coordenadas $19^{\circ} 56^{\prime} 45^{\prime \prime} \mathrm{S}$ de latitude e $48^{\circ} 02^{\prime} 15^{\prime \prime} \mathrm{W}$ de longitude. A região apresenta precipitação média anual de 1.200 a $1.500 \mathrm{~mm}$ e temperaturas médias entre 21 e $22^{\circ} \mathrm{C}$ (Prado, 1997).

A área escolhida para colheita da forragem foi uma gleba destinada à produção de feno, estabelecida em 1996 com capim-tifton 85 (Cynodon sp.), fertilizada com $358 \mathrm{~kg} / \mathrm{ha}$ da fórmula 30-00-20 (N-P-K) logo após o último corte que antecedeu o ensaio. A fertilização corretiva anual foi rezalizada objetivando-se atingir $30 \mathrm{ppm}$ de fósforo, $75 \%$ de saturação por bases e nível de potássio em torno de $5 \%$ da capacidade de troca catiônica.

As silagens foram confeccionadas entre os dias 15 e 21 de fevereiro de 2000. As condições climáticas predominantes nesses dias foram satisfatórias, com temperatura média de $26,5^{\circ} \mathrm{C}$ em momentos de estiagem e umidade relativa média do ar de $73 \%$. A forragem foi colhida com idade fisiológica equivalente a 35 dias de crescimento vegetativo, por meio de ceifa com uma segadora condicionadora (CASE, modelo $8850 \mathrm{HP}$ ), equipada com condicionador de rolos de metal com arestas reentrantes de formato helicoidal. O material foi submetido a emurchecimento visando obter teores crescentes de matéria seca na ensilagem. O monitoramento do teor de matéria seca do material exposto no campo foi realizado com uso do forno de microondas, até atingir a estabilização, segundo metodologia proposta por Pastorine et al. (2002). Quando o teor de matéria seca pretendido foi alcançado, o material foi picado a $8 \mathrm{~cm}$, enfardado em forma cúbica ( $140 \mathrm{~cm}$ comprimento x $120 \mathrm{~cm}$ de largura $\times 70 \mathrm{~cm}$ de altura), mediante o uso de enfardadora, (CLAAS, modelo Quadrant 1200 RC) e imediatamente envolvido (embaladora, marca REKORD, modelo Q-Pack 120) com seis camadas de filme plástico adesivo (TRIOPLAST $\mathrm{AB}$, modelo Triowrap, $75 \mathrm{~cm} \mathrm{x} \mathrm{0,0025} \mathrm{cm),} \mathrm{com} \mathrm{50 \%} \mathrm{de}$ sobreposição.

Os tratamentos consistiram de cinco silagens 200-300,300-400, 400-500, 500-600 e 600-700 g/kg MS com com respectivos pesos e densidades: $364 \mathrm{~kg}$ e $310 \mathrm{~kg} / \mathrm{m}^{3}$, $368 \mathrm{~kg} \mathrm{e} 313 \mathrm{~kg} / \mathrm{m}^{3}, 368 \mathrm{~kg} \mathrm{e} 313 \mathrm{~kg} / \mathrm{m}^{3}, 344 \mathrm{~kg}$ e $292 \mathrm{~kg} / \mathrm{m}^{3}$, $254 \mathrm{~kg}$ e $216 \mathrm{~kg} / \mathrm{m}^{3}$-semaditivo (SA) bacteriano-enzimático; três com aditivo (CA) (Sil-All - ALLTECH INC.) (ABE) - teores de matéria seca baixo, médio e alto: 200-300, 400-500 e 600-700 g/kg MS, com respectivos pesos e densidades: $352 \mathrm{~kg} \mathrm{e} 300 \mathrm{~kg} / \mathrm{m}^{3}, 329 \mathrm{~kg}$ e $280 \mathrm{~kg} / \mathrm{m}^{3}, 294 \mathrm{~kg}$ e $250 \mathrm{~kg} / \mathrm{m}^{3}$ - e uma confeccionada com fardos de capim emurchecido até atingir o maior nível de MS (600-700 g/kg MS), pulverizados externamente com $0,011 \mathrm{~mL} / \mathrm{cm}^{2}$ de ácido propiônico tamponado (APT), antes do revestimento com filme plástico.

Portanto, os tratamentos foram constituídos de distintas concentrações de MS, sem ou com aditivo bacterianoenzimático (SA e CA, respectivamente): 250SA, 350SA, 450SA, 550SA, 650SA, 250CA, 450CA, 650CA e 650APT. As amostras foram colhidas antes da ensilagem (zero hora) e nos tempos 6,12 horas e 1,2, 4, 8, 16,32,90 e 180 dias após a ensilagem, a fim de se estabelecer a tendência das características de fermentação e composição química.

$\mathrm{O}$ inoculante utilizado apresentou os seguintes níveis de garantia declarados: $1,0 \times 10^{9}$ unidades formadoras de colônias (UFC) de Streptococcus faecium/g; $1,0 \times 10^{9}$ UFC de Lactobacillus plantarum/g; $1,0 \times 10^{8}$ UFC de Pediococcus acidilactici/g e as enzimas hemicelulase, celulase e amilase. Dois litros e meio de solução a $5 \mathrm{~g} / \mathrm{L}$ foram aplicados por tonelada de forragem, conforme recomendação do fabricante. Essa solução foi aspergida, utilizando-se um sistema de bomba de diafragma ligada a dois bicos aspersores acoplados à plataforma de recolhimento da enfardadora imediatamente antes do enfardamento da forragem.

Os fardos foram amostrados empregando-se um amostrador do tipo "core sampler" $(50 \mathrm{~cm}$ de comprimento x $6 \mathrm{~cm}$ diâmetro) acoplado a uma motosserra. Amostras foram tomadas antes (zero hora) e nos tempos 6,12 horas e $1,2,4,8,16,32,90$ e 180 dias após o revestimento dos fardos com filme plástico. Foram coletadas amostras da forragem que deu origem a cada tratamento no momento da ceifa do material. Os dados obtidos foram utilizados como covariável para a avaliação da evolução temporal dos tratamentos. Nas amostragens ocorridas aos 90 e 180 dias, não foram amostrados os tratamentos 350SA, 250CA e 650APT. A leitura da temperatura dos fardos $\left({ }^{\circ} \mathrm{C}\right)$ foi tomada nas porções superior e interna de cada fardo, no momento da amostragem, utilizando-se um termômetro de bulbo de mercúrio acoplado a uma sonda.

As leituras de $\mathrm{pH}$ foram tomadas com o uso de um potenciômetro no extrato aquoso, formado por uma fração de $25 \mathrm{~g}$ de amostra misturada a $450 \mathrm{~mL}$ de água deionizada. As amostras tomadas imediatamente antes (zero hora) e aos $32 \mathrm{e}$ 180 dias após a ensilagem, para determinação do teor de matéria seca (TMS), da condutividade elétrica (CE) e do nitrogênio amoniacal $\left(\mathrm{N}^{-\mathrm{NH}_{3}}\right)$. Oteor dematéria seca $(\mathrm{g} / \mathrm{kg} \mathrm{MS})$ 
foi estimado após secagem em estufa de circulação forçada $\left(55^{\circ} \mathrm{C}\right)$, seguida de correção a $105^{\circ} \mathrm{C}$. O teor de N-NH $3(\mathrm{~g} / \mathrm{kg} \mathrm{N})$ foi determinado pela metodologia descrita por Chaney \& Marbach (1962) e a condutividade elétrica (CE $\mu \mathrm{s} / \mathrm{cm})$, por meio de um condutivímetro CA150 (MS Tecnopon Instrumentação), segundo metodologia descrita por Kraus et al. (1997).

Amostras foram enviadas ao Setor de Bactérias Oportunistas do Departamento de Microbiologia do Instituto de Ciências Biomédicas da USP (São Paulo/SP), para contagem de colônias, onde foram submetidas a três meios de cultura distintos: a) Agar Sangue em BHI (cultura em anaerobiose); b) Tryptic Soy Agar (cultura em aerobiose) e MacConkey (meio seletivo para "Enterobacteriacea"). Amostras também foram enviadas para o Laboratório de Fungos Toxicogênicos e Micotoxinas do Departamento de Microbiologia, Instituto de Ciências Biomédicas, Universidade de São Paulo (São Paulo/SP), para contagem, isolamento e idenficação da microbiota fúngica, utilizando-se a medotologia descrita por Swanson et al. (1992). Nas mesmas amostras de silagens, foram determinadas a atividade de água ( $\mathrm{Aa}$ ) por meio do medidor Aqualab CX2 (Decagon Devices, Inc. Pullman, Washington, USA).

A avaliação de perdas foi mensurada indiretamente pela estabilidade aeróbia nas amostras coletadas aos 32, 90 e 180 dias após a ensilagem. O material foi colocado em balde plástico, após a amostragem dos fardos, e mantido à temperatura ambiente, em sala fechada. As temperaturas das silagens e do ambiente foram tomadas de 12 em 12 horas, ou seja, no início da manhã e no final da tarde. Os parâmetros determinados foram: temperatura máxima $\left({ }^{\circ} \mathrm{C}\right)$; dias para atingir a temperatura máxima (dias); e acúmulo de temperatura acima da temperatura ambiente $\left({ }^{\circ} \mathrm{C}\right)$, durante o período de 5 a 10 dias após a abertura dos fardos. A avaliação da estabilidade aeróbia seguiu a metodologia descrita por O'Kiely et al. (1999b).

O delineamento estatístico utilizado foi o inteiramente casualizado, com três repetições, em esquema fatorial $5 \times 2$ incompleto, em parcelas subdivididas no tempo, em que o fator da parcela são os tratamentos (250SA, 350SA, 450SA, 550SA, 650SA, 250CA, 450CA, 650CA e 650APT) e o da subparcela, o tempo (zero hora e 32, 90 e 180 dias). Além dos fatores, foi incorporado ao modelo, como covariável, o teor de matéria seca dos fardos amostrados. O modelo proposto foi analisado pelo PROC GLM e os valores médios foram estimados pelo LSMEANS, ambos do SAS (SAS, 1988). Para comparações específicas de grupos de tratamentos, aplicou-se o teste $\mathrm{F}$ para contrastes, a partir do desdobramento dos graus de liberdade. A partir dessas análises compararam-se os tratamentos com e sem aditivos, bem como o tratamento 650APT, com (650CA) e sem(650SA) aditivo bacteriano-enzimático. Também foram calculados os coeficientes de correlação de Pearson entre os parâmetros estudados, utilizando-se o mesmo pacote estatístico.

\section{Resultados e Discussão}

Consta na Tabela 1 a evolução da contagem de bactérias ao longo do tempo de estocagem das silagens, realizada nos três meios de cultura seletivos para os microrganismos denominados aeróbios, anaeróbios e enterobactérias.

No caso de maior contagem microbiana (aeróbios), houve efeito significativo do teor de $\mathrm{MS}(\mathrm{P}<0,05)$, porém, a interação teor de MS $\times$ tempo de estocagem não foi significativa $(\mathrm{P}>0,05)$ e, por isso, foi calculada a média geral por tratamento (Tabela 1). Os tratamentos cujos teores de MS foram elevados (650SA, 650CA e 650APT) apresentaram valores inferiores $(\mathrm{P}<0,05)$ para contagem microbiana (aeróbios) em relação àquelas com teores de MS intermediários (350SA, 450SA e 550SA) e reduzidos (250CA e 350SA), à exceção do tratamento 250SA.

O comportamento dos aeróbios contraria as informações de McDonald et al. (1991) de que existe tendência de aumento na contagem de aeróbios com o aumento do teor de MS, em razão da maior aeração do material, uma vez que a compactação é dificultada no processo de ensilagem. Entretanto, quando se avalia a silagem confeccionada em forma de fardos grandes, a elevada pressão exercida pelo equipamento minimiza o risco de compactação insatisfatória.

Pelo teste de contrastes aplicado sobre a média dos teores de MS, tanto o uso do aditivo (CA) quanto o de APT não alteraram a contagem de microrganismos aeróbios $(\mathrm{P}>0,05)$, contrariando os relatos de Pitt (1990), que apontou redução no crescimento microbiano com o uso de APT. Contudo, a não-observância de resultados positivos neste experimento com o uso do APT pode estar associada à forma de aplicação, que, no caso, restringiu-se à superfície externa do fardo, na interface com o revestimento plástico.

Nos tratamentos sem ABE (SA), houve tendência de redução na contagem de aeróbios ao longo do tempo (de 7,96 para 5,69, respectivamente, de 0 a 180 dias), com exceção do tratamento $650 \mathrm{SA}$, porém sem resposta significativa $(\mathrm{P}>0,05)$. Nos tratamentos contendo $\mathrm{ABE}(\mathrm{CA})$, houve aumento na contagem entre 0 hora e 32 dias e redução entre 32 e 180 dias. O uso de APT acarretou redução na contagem dos aeróbios ao longo do tempo, provavelmente em razão dos menores valores de $\mathrm{pH}$ e Aa, condição restritiva para o crescimento dos microrganismos aos 180 dias. 


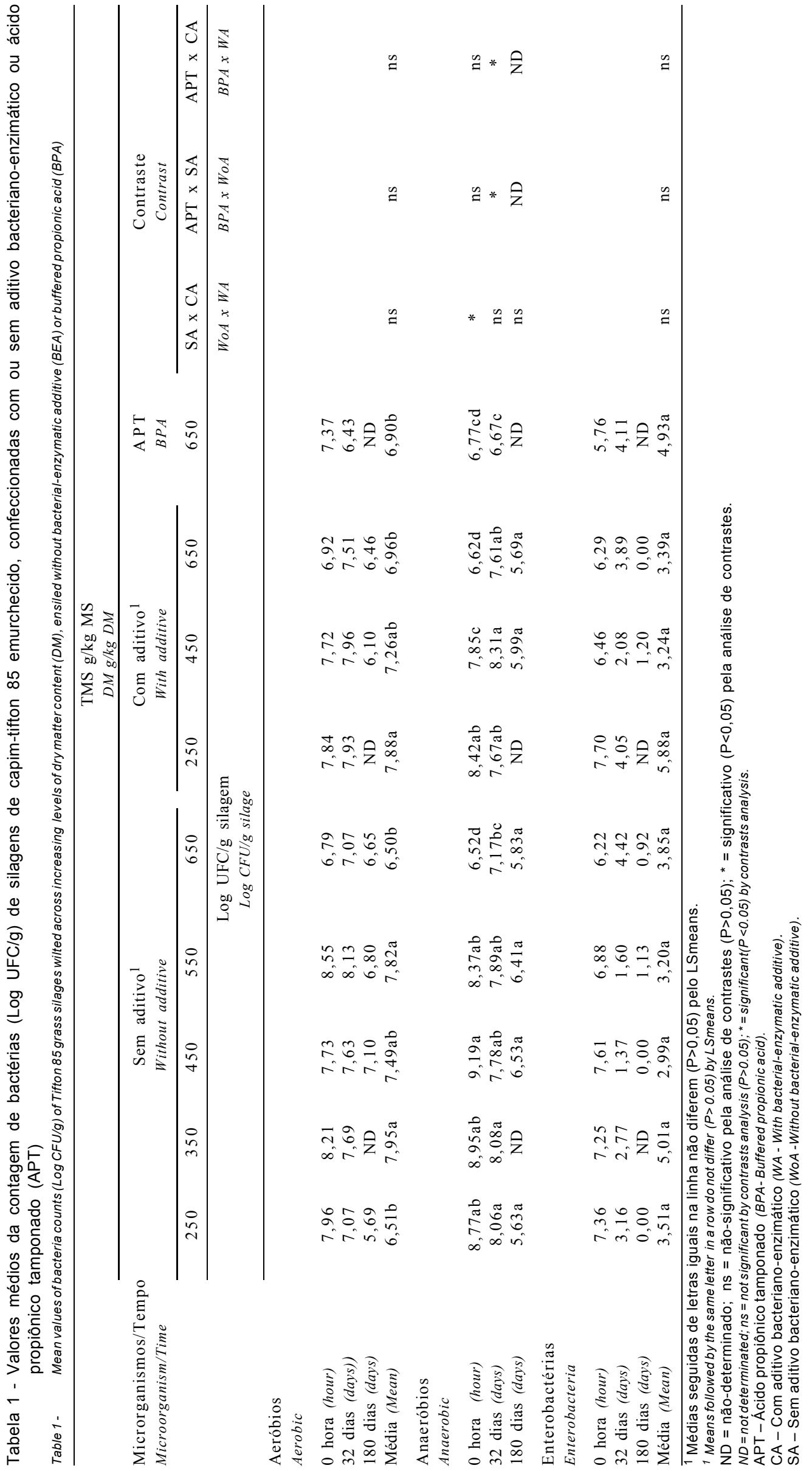


A contagem de microrganismos anaeróbios apresentou menores valores $(\mathrm{P}<0,05)$ para o maior teor de MS (650SA, 650CA, 650APT) nos tempos 0 hora e 32 dias, à exceção do tratamento 650APT aos 32 dias (Tabela 1). A contagem de microrganismos anaeróbios correlacionou-se negativamente com o $\mathrm{pH}(\mathrm{r}=-0,86)$ aos 32 dias. Com isso, o aumento no teor de MS restringiu o crescimento de microrganismos anaeróbios, como descrito por McDonald et al. (1991). Aos 180 dias, não houve diferença $(\mathrm{P}>0,05)$ na contagem de anaeróbios entre os tratamentos avaliados, provavelmente em decorrência das condições restritivas do meio em todos os tratamentos.

Com base nas análises de contrastes, constatou-se que, na interação $\mathrm{SA} \times \mathrm{CA}$, houve redução $(\mathrm{P}<0,05)$ da contagem de anaeróbios à zero hora pelo uso de $\mathrm{ABE}(\mathrm{CA})$, não se alterando $(\mathrm{P}>0,05)$ aos 32 e 180 dias após a ensilagem. O uso de APT não alterou $(\mathrm{P}>0,05)$ a contagem de anaeróbios, à zero hora, em relação àqueles com mesmo teor de MS (650SA e 650CA), porém reduziu $(\mathrm{P}<0,05)$ esse parâmetro na avaliação aos 32 dias, corroborando os relatos de Pitt (1990).

Nos tratamentos sem o uso do $\mathrm{ABE}$ (SA), à exceção tratamento 650SA, houve tendência de redução na contagem de anaeróbios ao longo do tempo, porém sem diferença significativa. Com uso de ABE (CA), houve aumento na contagem entre zero hora e 32 dias e redução entre 32 e 180 dias, demonstrando que o $\mathrm{ABE}$ favoreceu inicialmente o crescimento microbiano nas silagens e, posteriormente, a redução no número de microrganismos, provavelmente em decorrência das condições restritivas impostas pelo meio. A utilização de APT promoveu redução na contagem dos anaeróbios ao longo do tempo, evidenciando restrição ao crescimento destes microrganismos. McDonald et al.(1991) mencionaram que a avaliação da contagem total de anaeróbios, sem a identificação dos microrganismos, é passível de interpretações distorcidas, pois desse grupo fazem parte tanto as bactérias de crescimento desejável (como as bactérias láticas) quanto as indesejáveis (como os clostrídeos e as enterobactérias).

$\mathrm{Na}$ contagem relativa, as enterobactérias não apresentaram efeito significativo $(\mathrm{P}>0,05)$ do teor de MS e da interação teor de $\mathrm{MS} \times$ tempo de estocagem e, por isso, foi calculada a média geral por tratamento (Tabela 1). Pela análise de contrastes, constatou-se que não houve alteração na contagem de enterobactérias com o uso de $\mathrm{ABE}(\mathrm{P}>0,05)$. Tanja \& Juha (1999) também não verificaram alteração nas contagens de enterobactérias com o uso de inoculante bacteriano. Meeske et al. (1999), por sua vez, observaram menor contagem de enterobactérias na silagem emurchecida de Digitaria eriantha (388 g/kg MS) com o uso de ABE. O uso de APT não alterou
$(\mathrm{P}>0,05)$ a contagem de enterobactérias em relação aos demais tratamentos avaliados, provavelmente em razão dos elevados coeficientes de variação. As contagens médias sofreram significativa redução ao longo dos tempos de estocagem, observando-se praticamente ausência de enterobactérias aos 180 dias, o que caracteriza as condições restritivas ao seu crescimento em quase todos os tratamentos. Nos tratamentos com menores teores de matéria seca, provavelmente esse efeito tenha sido ocasionado pela redução do $\mathrm{pH}$ e, naqueles maiores teores de matéria seca, pela diminuição da Aa, confirmando os relatos de McDonald et al. (1991). Redução na contagem de enterobactérias ao longo do tempo de armazenamento e ausência após 44 dias de ensilagem também foram observadas por Meeske et al. (1999). O crescimento de enterobactérias é indesejável, pois esses microrganismos fermentam carboidratos a ácido acético e apresentam habilidade para degradar aminoácidos. A contagem de enterobactérias não esteve significativamente $(\mathrm{P}>0,05)$ correlacionada ao conteúdo de nitrogênio amoniacal em nenhum dos tempos de armazenagem estudados. Portanto, o aumento no teor de nitrogênio amoniacal das silagens, ao longo do tempo, não pode ser atribuído à ação destes microrganismos. A ação proteolítica poderia também estar associada à presença específica de clostrídeos e à ação de enzimas da própria planta, que geralmente são co-responsáveis pelo incremento no teor de nitrogênio amoniacal nas silagens com menor teor de MS (250SA e 250CA) em condições de ambiente não restritivas (pHe Aa) (Tabela 2).

Os fungos que cresceram no meio de cultura foram isolados e identificados nos seguintes grupos: Aspergillus sp., Fusarium sp., Geotrichum sp., Penicillium sp., dematiáceos e fungos não-esporulados (FNE). Contudo, os teores de MS estudados não influenciaram $(\mathrm{P}>0,05)$ as contagens dos grupos de fungos e leveduras. Como as interações entre teor de MS e tempo de estocagem não foram significativas $(\mathrm{P}>0,05)$, calcularam-se as médias por tratamento. Os valores médios nos tratamentos 250SA a 650SA para Aspergillus sp. variaram de 0,67 a $0,92 \mathrm{UFC} / \mathrm{g}$ silagem e, no tratamento $450 \mathrm{CA}$, de $0,67 \mathrm{UFC} / \mathrm{g}$ silagem. Os valores de Fusarium sp. variaram de 0,39 a 1,27 UFC/g silagem nos tratamentos 250SA a 650SA e de 0,74 a 1,26 UFC/g silagem nos tratamentos 250CA, 650CA e 650APT. Os valores de Geotrichum sp. variaram de 1,92 a 4,18 UFC/g silagem nos tratamentos 250SA a $650 \mathrm{SA}$ e de 1,43 a 4,85 $\mathrm{UFC} / \mathrm{g}$ silagem nos tratamentos $250 \mathrm{CA}$ a $650 \mathrm{CA}$.

Pela análise de contrastes, o uso de $\mathrm{ABE}$ e de APT não alterou $(\mathrm{P}>0,05)$ as contagens de leveduras e fungos.

A contagem de Geotrichum esteve positivamente correlacionada ao $\mathrm{pH}(\mathrm{r}=0,70)$, à Aa (atividade de água) 


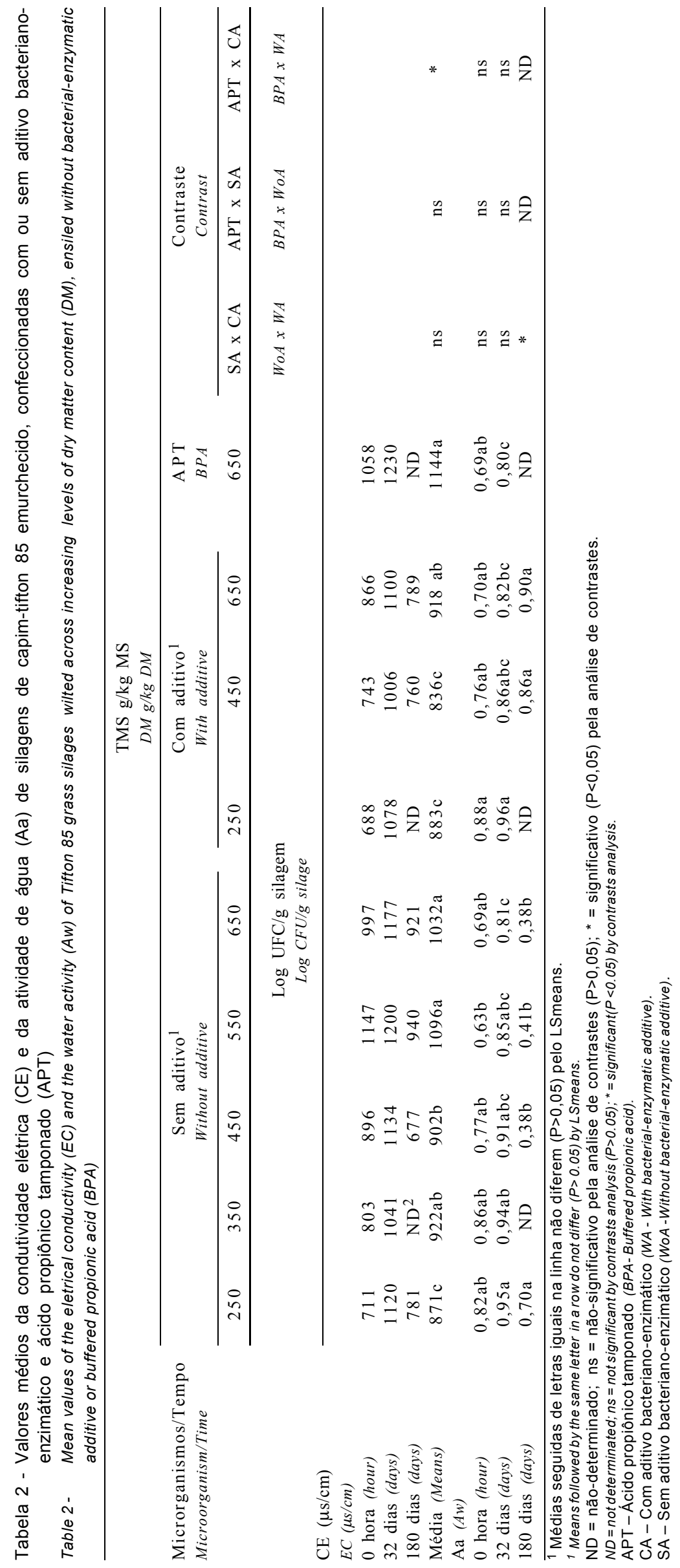


$\mathrm{r}=0,75$ e à relação de Aa com a umidade $(\mathrm{r}=0,80)$ aos 180 dias. $\mathrm{O}$ pH e Aa apresentaram correlações positivas com a umidade ( $r=0,85$ e $r=0,80$, respectivamente) nesse tempo de estocagem (180 dias), caracterizando a alteração na população de fungos ao longo do tempo. Leveduras, Aspergillus sp. e Penicillium sp. apresentaram contagem próxima de zero na amostragem inicial e ausência nos demais tempos de estocagem (32 e 180 dias), enquanto Fusarium sp., dematiáceos e FNE, baixa contagem no tempo zero hora e ausência nos demais tempos de estocagem. A contagem de Geotrichum sp. foi nula no momento de estocagem e apresentou valores consideráveis aos 32 e 180 dias. Dessa forma, no momento da estocagem (zero hora), houve ausência de Geotrichum sp. e mínima contagem dos demais e nos demais tempos (32 e 180 dias), crescimento de Geotrichum sp. e ausência dos demais grupos. Umaña et al. (1991) e Meeske et al. (1999) observaram redução nas contagens de leveduras e fungos com o aumento do tempo de estocagem das silagens. McDonald et al. (1991) relataram que altas contagens de fungos e leveduras são indesejáveis, pois esses microrganismos são os principais responsáveis pela deterioração aeróbia das silagens após a abertura do silo. A ocorrência dos gêneros de fungos isolados neste estudo é compatível com os resultados da literatura (McDonald et al., 1991).

O comportamento apresentado pelo Geotrichum sp demonstrou que esses fungos são mais tolerantes às condições restritivas de meio, ou seja, sobrevivem em menores atividades de água (<Aa) que os demais gêneros isolados. Segundo Leitão (1997), o crescimento de leveduras é geralmente restringido por valores de Aa inferiores a 0,88 e o dos fungos, por valores inferiores a 0,80. Entretanto, pelos valores de Aa verificados (Tabela 2) neste trabalho, houve grande variação entre os gêneros de fungos detectados quanto à tolerância de valores baixos de Aa. Em condições de Aa inferiores a 0,80, supostamente haveria limitação ao crescimento de fungos, no entanto, houve crescimento. Embora o emurchecimento e o uso de $\mathrm{ABE}$ (CA) não tenham alterado as contagens de leveduras e fungos, existem relatos de alteração nas contagens desses microrganismos pela adoção dessas práticas. O'Kiely et al. (1999b) observaram aumento na contagem de leveduras e Umaña et al. (1991), na contagem de leveduras e fungos, como resultado do emurchecimento. Meeske et al. (1999) observaram menores contagens de leveduras e fungos na silagem pré-emurchecida de Digitaria eriantha (388 g/kg MS), em decorrência do uso de ABE. Tanja \& Juha (1999), no entatnto, não encontraram alteração nas contagens de leveduras e fungos com o uso de inoculante bacteriano.
A condutividade elétrica (CE) aumentou no intervalo de 0 a 32 dias de armazenamento, mas decresceu no período de 32 a 180 dias, independentemente do uso de ABE (CA) e APT (Tabela 2). Não houve interação significativa $(\mathrm{P}>0,05)$ de teor de MS e tempo de estocagem sobre a CE e, por isso, avaliaram-se as médias por tratamento (Tabela 2). Pela média geral, os tratamentos com maiores conteúdos de MS $(550$ e $650 \mathrm{~g} / \mathrm{kg} \mathrm{MS})$ apresentaram maiores valores $(\mathrm{P}<0,05)$ para $\mathrm{CE}$, demonstrando que houve maior lise celular para os maiores teores de MS, como observado em revisões relatas por Balsalobre et al. (2001). O uso de ABE (CA) reduziu $(\mathrm{P}<0,05)$ a $\mathrm{CE}$ apenas no nível intermediário de MS (450 g/kg MS), entretanto, pela análise das médias dos teores de MS, o uso de $\mathrm{ABE}$ não alterou $(\mathrm{P}>0,05)$ a $\mathrm{CE}$.

A utilização de APT não alterou $(\mathrm{P}>0,05)$ a $\mathrm{CE}$ em relação ao tratamento $650 \mathrm{SA}$, sendo superior $(\mathrm{P}<0,05)$ ao tratamento 650CA pela análise de contrastes.

Nas silagens não-inoculadas, a tendência da atividade de água (Aa) foi semelhante à da $\mathrm{CE}$ ao longo do tempo (Tabela 2). A CE esteve, inclusive, negativamente correlacionada à Aa, nos tempos zero hora $(r=-0,71)$ e aos 180 dias $(r=-0,75)$. Nas silagens tratadas com ABE e APT, houve tendência de aumento da Aa ao longo do tempo. Praticamente não houve diferença entre tratamentos quanto ao efeito dos teores de MS sobre a Aa no momento da estocagem. Entretanto, na avaliação aos 32 dias, as silagens com o menor teor de MS (250 g/kg MS) apresentaram os maiores valores $(\mathrm{P}<0,05)$ de Aa. Pela análise de contrastes, o uso de $\mathrm{ABE}$ ou APT não alterou $(\mathrm{P}>0,05)$ os valores da $\mathrm{Aa}$ até 32 dias após a ensilagem. Na avaliação aos 180 dias, para as silagens sem $\mathrm{ABE}$, o menor teor de matéria seca $(250 \mathrm{~g} / \mathrm{kg} \mathrm{MS})$ apresentou valor superior $(\mathrm{P}<0,05)$ ao dos demais, que não diferiram entre si. Nas silagens inoculadas, não houve redução na Aa com o incremento do teor de MS e os valores apresentados foram superiores aos valores médios para os respectivos teores de MS na ausência de $\mathrm{ABE}$ (SA). Assim, pela análise de contrastes, constatou-se que a Aa foi aumentada $(\mathrm{P}<0,05)$ com o uso do aditivo bacteriano-enzimático, possivelmente pela ruptura de células do tecido vegetal causada pela atividade de enzimas presentes no aditivo.

A atividade de água (Aa) esteve positivamente correlacionada ao $\mathrm{pH}(\mathrm{r}=0,79)$ aos 180 dias. Dessa forma, o incremento no teor de MS reduziu a Aa nas silagens, como relatado por McDonald et al. (1991) e Leitão (1997). A aplicação de $\mathrm{ABE}$ proporcionou o incremento nos valores finais de Aa aos 180 dias de estocagem, criando condições mais favoráveis ao crescimento de microrganismos indesejáveis. A Aa fornece indicação segura do teor de água livre 
do alimento, sendo a única forma de água possível de utilização pelos microrganismos. No entanto, segundo Leitão (1997), o comportamento desses microrganismos frente à Aa é extremamente variável, dependendo da espécie ou da cepa considerada, do substrato no qual se encontra e da relação entre a Aa e os outros fatores intrínsecos ou extrínsecos. As bactérias, as leveduras e os fungos normalmente necessitam de valores de Aa superiores a 0,$90 ; 0,88$; e 0,80 , respectivamente, para que haja crescimento satisfatório (Leitão, 1997). Entretanto, neste estudo esses limites não foram respeitados. É importante salientar que Aa esteve positivamente correlacionada às contagens de Geotrichum $(\mathrm{r}=0,75)$ aos 180 dias após a ensilagem. Leitão (1997) destacou que alimentos com valores de Aa inferiores a 0,6 estariam livres da possibilidade de deterioração microbiana, embora isso não indique a necessária eliminação dos microrganismos contaminantes. Portanto, a presença de microrganismos sob baixos valores Aa não significa que estejam ativos.

A deterioração aeróbia das silagens é indesejável por estar associada à grande perda de nutrientes, resultando em baixo consumo e até mesmo em rejeição completa desse alimento pelos animais (McDonald et al., 1991). As perdas após a abertura do silo dependem do manejo imposto ao silo, mas a extensão de deterioração do material está relacionada à estabilidade aeróbia da silagem (Nussio et al., 2002).

$\mathrm{Na}$ Tabela 3 são apresentados os resultados referentes aos valores de temperatura. Constatou-se tendência de redução da temperatura máxima entre 32 e 90 dias e de aumento entre 90 e 180 dias de estocagem, de modo semelhante ao observado para temperatura ambiente. Harrison et al. (1999) verificaram que o incremento da temperatura ambiente $\left(15,25\right.$ e $\left.35^{\circ} \mathrm{C}\right)$ apresentou efeito negativo sobre a estabilidade aeróbia da silagem de milho, resultando em menor tempo para perda da estabilidade e aumento da temperatura média das silagens. Nos primeiros momentos de avaliação (32 e 90 dias), foram observadas maiores temperaturas nos tratamentos com o menor teor de MS (250SA e 250CA). Aos 180 dias, a mais alta temperatura foi observada no tratamento 450SA, contudo sem diferença estatística. Pela análise de contrastes, o uso de $\mathrm{ABE}$ (CA) não alterou $(\mathrm{P}>0,05)$ a temperatura das silagens aos 32 e 90 dias, mas reduziu $(\mathrm{P}<0,05)$ aos 180 dias.

A temperatura $\left({ }^{\circ} \mathrm{C}\right)$ aos 32 dias apresentou correlação positiva com o teor de $\mathrm{N}-\mathrm{NH}_{3}(\mathrm{r}=0,84)$, observando-se os maiores valores para as silagens de alta umidade. Aos 180 dias, o valor da temperatura foi positivamente correlacionado à $\mathrm{Aa}(\mathrm{r}=0,81)$ e à contagem de Geotrichum $(\mathrm{r}=0,68)$. A temperatura máxima foi atingida aos 32 e 90 dias, reduzindo, posteriormente, aos 90 e 180 dias, possivelmente em razão da tendência semelhante da temperatura ambiente. Desse modo, as silagens apresentaram maior estabilidade aos 90 dias, quando a temperatura ambiente foi mais amena $\left(21^{\circ} \mathrm{C}\right)$. Não houve interação significativa $(\mathrm{P}>0,05)$ de teor de MS e tempo de estocagem (Tabela 3 ).

Os tratamentos 450CA e 550SA, nos tempos de estocagem de 32 e 90 dias, apresentaram os maiores tempos (em dias) para ocorrência do pico de temperatura, demonstrando efeito positivo do uso do aditivo (ABE), nos teores de MS. No entanto, pela análise de contrastes, o uso de ABE ou APT não alterou $(\mathrm{P}>0,05)$ esse parâmetro pela média dos teores de MS estudados. O tempo necessário para atingir a temperatura máxima apresentou correlação positiva com o $\mathrm{pH}(\mathrm{r}=0,76)$ e a temperatura máxima, em ${ }^{\circ} \mathrm{C}(\mathrm{r}=0,79)$, aos 180 dias após a ensilagem.

Constam na Tabela 4 os graus de temperatura acumulados acima da variação apresentada no ambiente, entre 0 e 5 dias e 0 e 10 dias de exposição ao ambiente aeróbio. Os valores observados foram reduzidos ao longo do tempo, provavelmente em razão da variação da temperatura ambiente e da maior estabilidade das silagens. Pelos resultados da temperatura acumulada com 32 dias de estocagem (entre 0 e 5 dias de exposição ao ambiente aeróbio), pode-se classificar os tratamentos em três grupos distintos: primeiro grupo, com os maiores acúmulos de temperatura (tratamentos 250SA, 250CA, 350SA e 450SA) $(\mathrm{P}<0,05)$; segundo grupo, com valores intermediários $(\mathrm{P}<0,05)$ ( 650SA, 650CA e 650APT); e terceiro grupo, com menores acúmulos de temperatura (450CA e 550SA). O uso do aditivo foi mais efetivo em controlar a temperatura da silagem em condições de aerobiose no grupo com teores de MS intermediários (450 g/kg MS), não sendo observados efeitos de tratamentos nos demais tempos de estocagem. No entanto, pela análise de contrastes, considerando-se a média dos teores de MS, o uso do aditivo (CA) não alterou $(\mathrm{P}>0,05)$ a temperatura acumulada no momento da ensilagem e aos 32 e 180 dias de estocagem, mas o uso de APT aumentou $(\mathrm{P}<0,05)$ o acúmulo de temperatura aos 32 dias de estocagem. A temperatura acumulada apresentou correlação positiva com temperatura máxima, $\mathrm{em}^{\circ} \mathrm{C}(\mathrm{r}=0,88)$, com $\mathrm{Aa}(\mathrm{r}=0,73)$ e com o teor de nitrogênio amoniacal $(\mathrm{r}=0,75)$ aos 32 dias.

No estudo da temperatura acumulada, entre 0 e 10 dias de exposição ao ambiente aeróbio, aos 32 dias após a ensilagem, foi possível agrupar os tratamentos em três grupos distintos $(\mathrm{P}<0,05)$ : um com os maiores acúmulos de temperatura (tratamentos 250SA, 250CA e 350SA); 


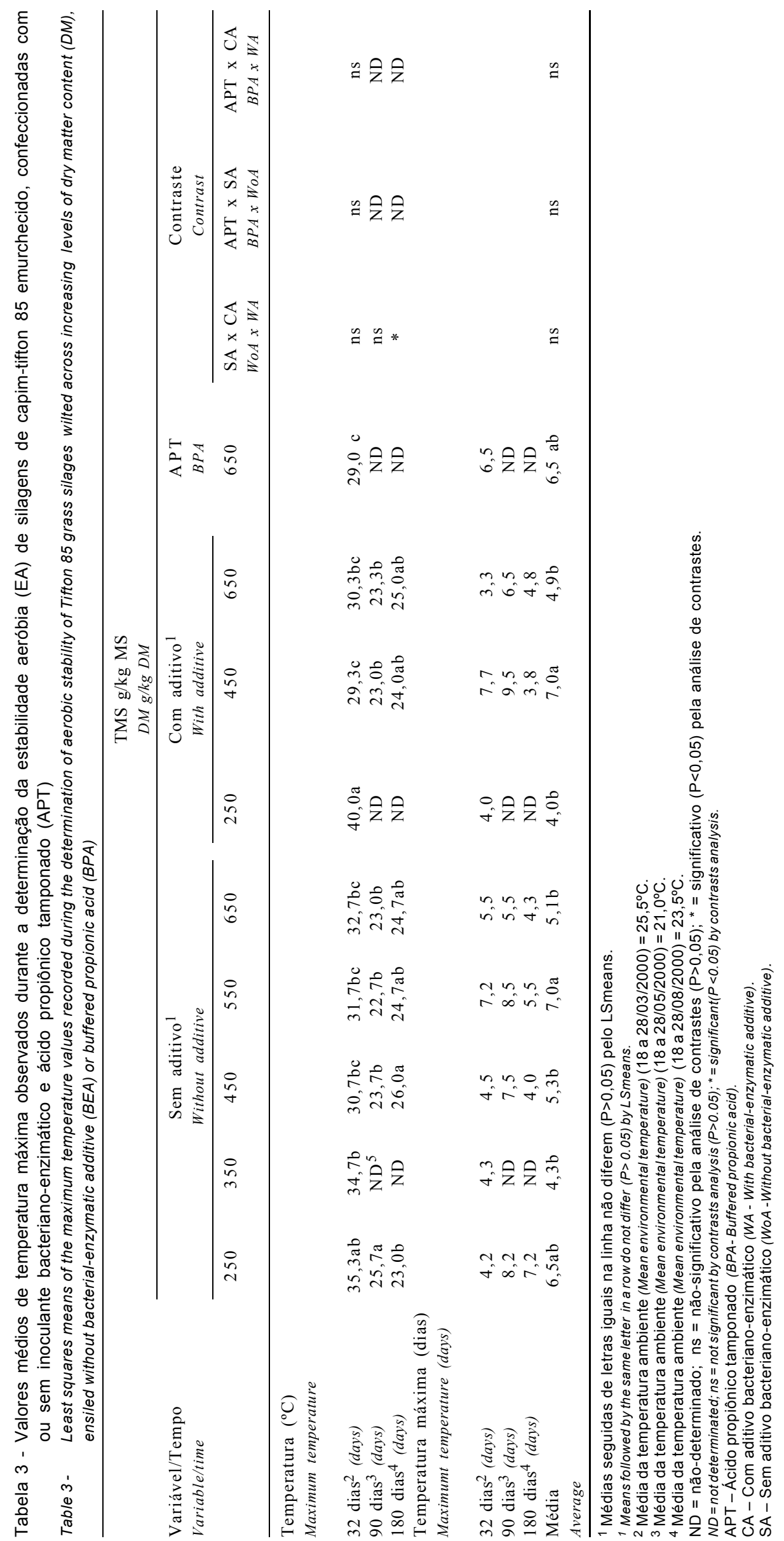


o segundo com os valores intermediários de temperatura (450SA, 450CA, 650SA, 650CA); e o terceiro, com menores acúmulos de temperatura (550SA e 650APT).

Contudo, os resultados de temperatura acumulada, pela análise de contrastes, não foram alterados $(\mathrm{P}>0,05)$ pelo uso do aditivo ou APT, aos 32 dias de estocagem, com significância estatística para os contrastes APT x AS e APT x CA. Constatou-se correlação positiva nesse período de estocagem com o conteúdo de nitrogênio amoniacal $(\mathrm{r}=0,81)$, $\mathrm{Aa}(\mathrm{r}=0,70)$, a temperatura máxima em ${ }^{\circ} \mathrm{C}(\mathrm{r}=0,92)$ e a temperatura em graus acumulados de $0-5$ dias $(r=0,96)$. Na avaliação ocorrida aos 90 dias de estocagem, não houve efeito de tratamentos. $\mathrm{O}$ uso do aditivo $(\mathrm{CA})$ não alterou $(\mathrm{P}>0,05)$ a temperatura acumulada aos 90 dias de estocagem. $\mathrm{Na}$ avaliação aos 180 dias, o tratamento 450SA apresentou média superior aos demais e o uso do aditivo reduziu $(\mathrm{P}<0,05)$ o acúmulo de temperatura, havendo correlação negativa com os graus acumulados entre $0-5$ dias $(\mathrm{r}=-0,75)$.

Em resumo, houve tendência de aumento da estabilidade aeróbia (EA) ao longo do tempo de estocagem, provavelmente em razão da redução da temperatura ambiente (Tabela 3). Portanto, com relação à estabilidade aeróbia, os tratamentos podem ser divididos em: menor $\mathrm{EA}(\mathrm{P}<0,05)=$ 250SA e 250CA, menos estáveis; $\mathrm{EA}$ intermediária $=350 \mathrm{SA}$ e 450SA; e maior $\mathrm{EA}=450 \mathrm{CA}, 650 \mathrm{SA}$, e $650 \mathrm{APT}$, porém não se diferenciando de 450SA, 550SA e 650SA. Desse modo, pode-se constatar que o emurchecimento a teores de MS superiores a $550 \mathrm{~g} / \mathrm{kg}$ MS determinou aumento na EA das silagens, em 7 dias, sem a ocorrência de deterioração em condições de aerobiose, o que normalmente manifestaria o aumento de temperatura e o aparecimento de mofos. O'Kiely (1999) e O'Kiely et al. (1999b) também observaram melhoria na EA de silagens de gramíneas emurchecidas de clima temperado. McDonald et al. (1991) ressaltaram que, apesar de a literatura sugerir que silagens com alto teor de MS podem ser mais susceptíveis à deterioração aeróbia, existem evidências de que a deterioração é reduzida em silagens com teor de MS superior a $500 \mathrm{~g} / \mathrm{kg}$ MS, o que pôde ser constatado neste experimento no tratamento com $550 \mathrm{~g} / \mathrm{kg}$ MS quanto à EA e à temperatura acumulada aos 32 dias, na avaliação de 0 a 5 dias, e aos 180 dias, na avaliação de 0 a 10 dias (Tabelas 3 e 4 ). O uso do aditivo no teor intermediário de MS (450 g/kg MS) também foi efetivo em aumentar a EA da silagem. Meeske et al. (1999) também observaram melhoria na EA de silagem emurchecida de Digitaria eriantha (388 g/kg MS) com a utilização de aditivo bacterianoenzimático e associaram essa melhoria aos menores teores de carboidratos solúveis e ácido lático e à baixa contagem de leveduras assimiladoras de lactato.
O uso do aditivo causa redução na estabilidade aeróbia de silagens de gramíneas tropicais (Nussio et al., 2002), provavelmente em razão do maior conteúdo de ácido lático dessas silagens, visto que as bactérias láticas inoculadas são homofermentativas. Os microrganismos aeróbios, como fungos, leveduras e Bacillus, degradam o ácido lático com facilidade após abertura do silo, gerando dióxido de carbono, etanol e ácido acético, além de grande liberação de calor (Lindgren, 1999).

Os valores de $\mathrm{pH}$ das silagens que foram reduzidos ao longo do período de armazenamento são apresentados na Tabela 5. O emurchecimento determinou menor intensidade no processo de fermentação, comprovada pelo aumento no $\mathrm{pH}$ da silagem com o incremento do teor de MS da forragem ensilada, corroborando com os relatos de McDonald et al. (1991) e Wyss (1999). Pela análise de contrastes, o uso de aditivo não alterou $(\mathrm{P}>0,05) \mathrm{o} \mathrm{pH}$ da silagem no momento, 32 e 180 dias após a ensilagem. Meeske et al. (1999) observaram que o uso de $\mathrm{ABE}$ foi efetivo em reduzir o $\mathrm{pH}$ da silagem quando aplicado em forragem emurchecida. Entretanto, O'Kiely et al. (1999a) não notaram alteração no pH de silagens de gramíneas emurchecidas de clima temperado decorrente do uso de inoculantes. Pela análise de contrastes (Tabela 5), o tratamento 650APT foi superior $(\mathrm{P}<0,05)$ ao $650 \mathrm{CA}$, aos 32 e 90 dias de estocagem, o que pode ser explicado pelo fato de o APT tratar-se de um produto tamponado, ocasionando maior $\mathrm{pH}$ final da silagem. Aos 180 dias de estocagem, o $\mathrm{pH}$ das silagens apresentaram correlação positiva com a $\mathrm{CE}(\mathrm{r}=0,98)$.

Os resultados dos teores de nitrogênio amoniacal das silagens (Tabela 5) apresentaram tendência de aumento com o tempo de estocagem e reduziram $(\mathrm{P}<0,05)$ com o incremento do teor de MS, estando de acordo com relatos de McDonald et al. (1991) e Wyss (1999b). Na análise de contrates, o teor de $\mathrm{N}-\mathrm{NH}_{3}$ foi superior $(\mathrm{P}<0,05)$ nos tratamentos com ABE, nos tempos 32 e 180 dias de estocagem. O'Kiely et al. (1999b), assim como Meeske et al. (1999), não observaram redução na concentração de $\mathrm{N}-\mathrm{NH}_{3}$ em silagens com o uso de inoculante bacteriano aplicado em condições desfavoráveis. Os resultados obtidos neste estudo demonstram que o uso de $\mathrm{ABE}$ não reduziu o teor de $\mathrm{N}-\mathrm{NH}_{3}$ das silagens quando aplicado à forragem in natura.

Considerando-se todos os parâmetros avaliados, as silagens podem ser divididas em dois grupos distintos: o primeiro, composto pelos tratamentos 450CA, 550SA, 650SA, 650CA e 650APT, por apresentar menores contagens de bactérias, valores intermediários de atividade de água (Aa) e $\mathrm{N}-\mathrm{NH}_{3}$, associados a maior condutividade 


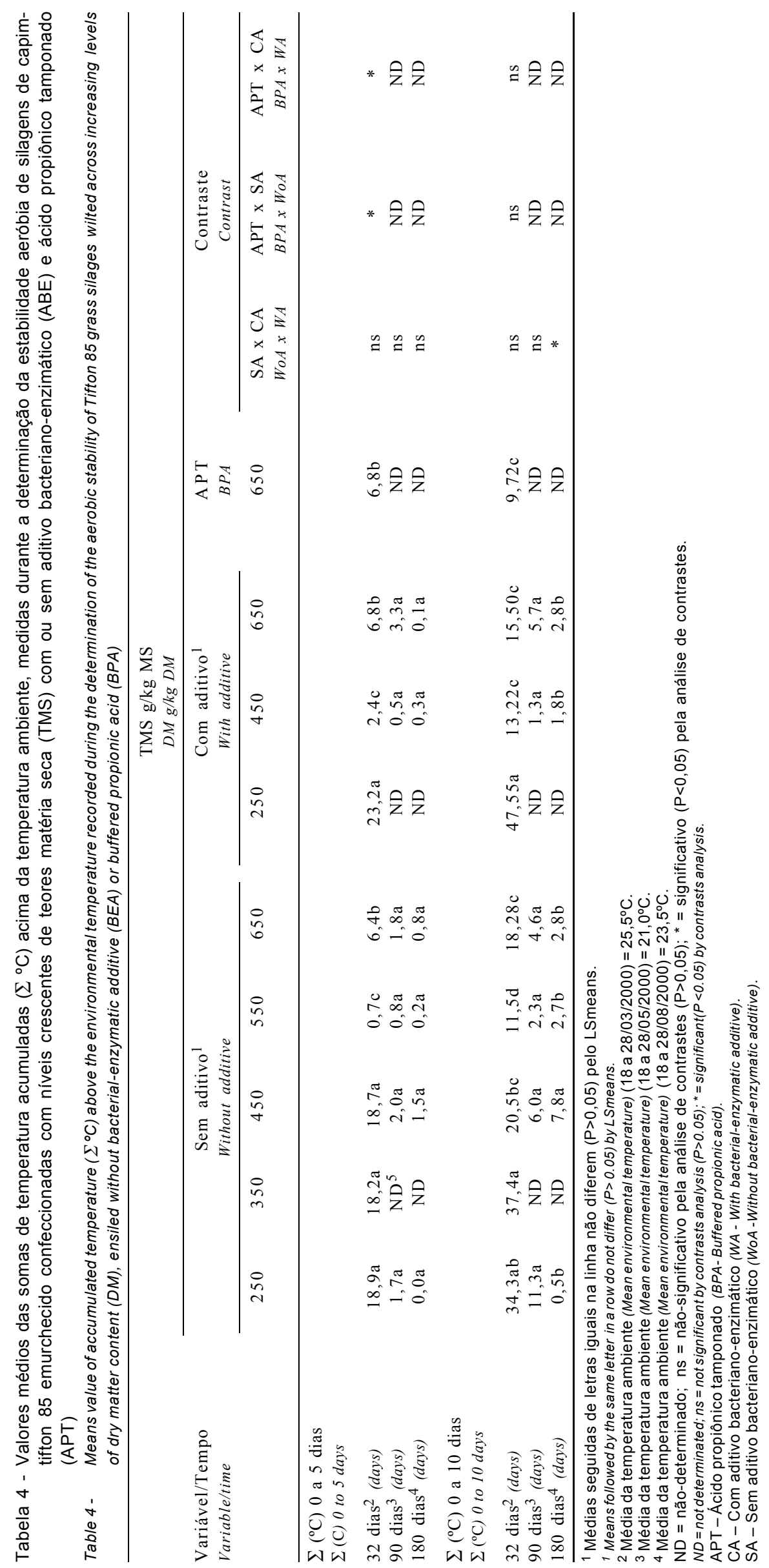




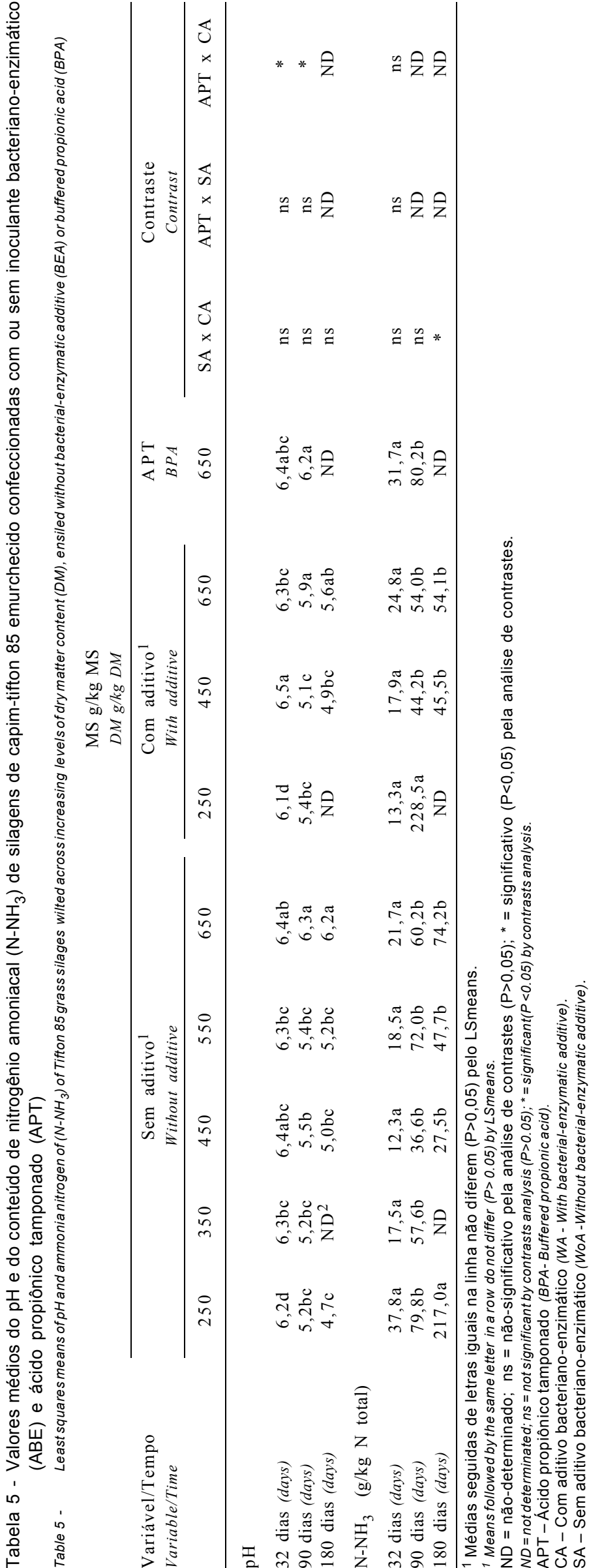

elétrica (CE) e pH e melhor estabilidade aeróbia (EA); e o segundo grupo, composto pelos tratamentos 250SA, 250CA, 350SA e 450SA, caracterizado pelos piores resultados dos parâmetros avaliados.

$\mathrm{O}$ aumento no teor de MS reduziu a Aa, restringindo o crescimento de bactérias e, conseqüentemente, diminuindo a intensidade de fermentação. $\mathrm{O}$ uso do aditivo promoveu efeitos positivos no processo de conservação somente para silagens contendo teores intermediários de MS (450 g/kg MS), principalmente aos 32 dias de estocagem.

\section{Conclusões}

O pré-emurchecimento da forragem a conteúdos de matéria seca superiores a $550 \mathrm{~g} / \mathrm{kg}$ MS reduziu a atividade da água, restringindo o crescimento de bactérias e, conseqüentemente, reduzindo a intensidade de fermentação, resultando em maior estabilidade aeróbica das silagens produzidas.

O uso de inoculante bacteriano-enzimático foi efetivo quando associado ao conteúdo inermediário de MS ( $450 \mathrm{~g} / \mathrm{kg} \mathrm{MS})$, resultando em maior estabilidade aerobica do material.

O uso de ácido propiônico tamponado não proporcionou melhorias no perfil microbiológico, nos parâmetros físicos e na estabilidade aeróbica das silagens.

\section{Agradecimento}

À Fazenda Água Comprida, pelo apoio irrestrito na realização deste estudo e por proporcionar condições operacional, financeira e de recursos humanos durante sua condução.

\section{Literatura Citada}

CHANEY, A.L.; MARBACH, E.P. Modified reagents for determination of urea and ammonia. Clinical Chemistry, v. 8, p.130-137, 1962.

HARRISON, S.; MOULD, F.L.; PHIPPPS, R.H. et al. The effect of ambient temperature on the rate and extent of aerobic deterioration in maize silages, and the subsequent effects on in vitro fermentation characteristics assessed using the Reading Pressure Technique (RPT). In: INTERNATIONAL SILAGE CONFERENCE, 7., 1999, Uppsala, 1999. Proceedings... Uppsala: Swedish University of Agricultural Science, 1999. p.298-299.

LEITÃO, M.F.F. Atividade de água e alterações microbiológicas dos alimentos. In: JARDIM, D.C.P.; GERMER, S.P.M. (Eds.) Atividade de água em alimentos. Campinas: Instituto de Tecnologia de Alimentos, 1997. p.1-18.

LINDGREN, S. Can HACCP principles be applied for silage safety? In: INTERNATIONAL SILAGE CONFERENCE, 7., 1999, Uppsala. Proceedings... Uppsala: Swedish University of Agricultural Science, 1999. p.51-66.

KRAUS, T.J.; KOEGEL, R.G.; STRAUB, R.J. et al. Leachate conductivity as index for quantifying level of forage conditioning. 
In: ASAE ANNUAL INTERNATIONAL MEETING, 44., 1997, Minneapolis. Proceedings... Minneapolis: ASAE, 1997. p.110 .

McDONALD, P.; HENDERSON, A.R.; HERON; S.J.E. Biochemistry of silage. 2.ed. Marlow: Chalcombe Publication, 1991. 340p.

MEESKE, R.; BASSON, H.M.; CRUYWAGEN, C.W. The effect of a lactic acid bacterial inoculant with enzymes on the fermentation dynamics, intake and digestibility of Digitaria eriantha silage. Animal Feed Science and Technology, v.81, p.237-248, 1999.

MUCK, R.E.; KUNG, L. Effects of silage additives on ensiling. In: Silage field to feedbunk, 1997, Ithaca. Procedings... Ithaca: NRAES, 1997. p.187-199.

NUSSIO, L.G.; PAZIANI, S.F.; NUSSIO, C.M.B. Ensilagem de capins tropicais. In.: REUNIÃO ANUAL DA SOCIEDADE BRASILEIRA DE ZOOTECNIA, 39., 2002. Recife. Anais... Recife: Sociedade Brasileira de Zootecnia, 2002. p.60-99.

O'KIELY, P. Conservation of unwilted and wilted grass trated with different additives and ensiled in laboratory silos. In: GRANGE RESEARCH CENTRE. Teagasc Research Report 1999. Dunsany: Teagasc, 1999. p.99.

O'KIELY, P.; FORRISTAL, D.; LENEHAN, J.J. Silage additives and their effects on the conservation characteristics of firstcut baled silage. In: GRANGE RESEARCH CENTRE. Teagasc Research Report 1999. Dunsany: Teagasc, 1999a. p.117-118.

O'Kiely, P.; MOLOneY, A.; KeAting, T. et al. Maximing output of beef within cost efficient, environmentally compatible forage conservation systems. Dunsany: Grange Reserch Centre, 1999b. 64p. (Beef Production Series, 10).

PASTORINI, L.H.; BACARIN, M.A.; ABREU, C.M. Secagem de material vegetal em forno de microondas para determinação de matéria seca e análise químicas. Ciência Agrotécnica, v.26, p.1252-1258, 2002

PITT, R.E. Silage and hay preservation. Ithaca: Northeast Regional Agricultural Engineering Service, 1990. 53p. (NRAES-5).
PRADO, H. Os solos do Estado de São Paulo: mapas pedológicos. Piracicaba: Escola Superior de Agricultura Luiz de Queiroz, 1997. $102 \mathrm{p}$

STATISTICAL ANALYSES SYSTEM - SAS. SAS user's guide, release 6.03 . Cary: 1988. $1028 \mathrm{p}$.

SWANSON, K.M.J.; BUSTA, F.F.; PETTERSON, E.H. et al. Colony count methods. In: VANDERZANT, C.; SPLITTSTOESSER, D.S. (Eds.) Compendium of methods for the microbiological examination of foods. New York: American Public Health Association, 1992. p.145-167.

TANJA, P.; JUHA, N. The effect of fermentation quality on the aerobic stability of direct cut or slighty prewilt grass silage. In: INTERNATIONAL SILAGE CONFERENCE, 7., 1999, Uppsala. Proceedings... Uppsala: Swedish University of Agricultural Science, 1999. p.280-281.

UMAÑA, R.; STAPLES, C.R.; BATES, D.B. et al. Effects of the digestibility of bermudagrass ensiled at two moisture contents. Journal of Animal Science, v.69, n.11, p.4588-4601, 1991.

VILELA, D. Aditivos para silagens de plantas de clima tropical. In: SIMPÓSIO SOBRE ADITIVOS NA PRODUÇÃO DE RUMINANTES E NÃO-RUMINANTES, Botucatu, 1998. Anais... Botucatu: Sociedade Brasileira de Zootecnia, 1998. p. $73-108$.

WYSS, U. Influence pre-wilting degree on aerobic stability of grass silages. In: INTERNATIONAL SILAGE CONFERENCE, 1999, 7., Uppsala. Proceedings... Uppsala: Swedish University of Agricultural Science, 1999b. p.284-285. 